08

\title{
Исследование влияния парциального давления кислорода на фазовый состав наночастиц оксида меди вакуумно-дугового синтеза
}

\author{
(C) А.В. Ушаков, ${ }^{1,2}$ И.В. Карпов, ${ }^{1,2}$ Л.Ю. Федоров, ${ }^{1,2}$ Е.А. Гончарова, ${ }^{1,2}$ М.В. Брунгардт, ${ }^{1}$ В.Г. Демин ${ }^{1}$ \\ ${ }^{1}$ Сибирский фредеральный университет, \\ 660041 Красноярск, Россия \\ ${ }^{2}$ Федеральный исследовательский центр Красноярский научный центр СО РАН, \\ 660036 Красноярск, Россия \\ e-mail: sfu-unesco@mail.ru
}

Поступило в Редакцию 25 мая 2021 г.

В окончательной редакции 9 августа 2021 г.

Принято к публикации 10 августа 2021 г.

\begin{abstract}
Исследовано влияние парциального давления кислорода (10-40\%) на физические свойства осаждаемых наночастиц оксида меди, полученных в плазме дугового разряда низкого давления. Анализ рентгеновской дифракции показал, что кубическая структура $\mathrm{Cu}_{2} \mathrm{O}$ меняется на моноклинную $\mathrm{CuO}$ при увеличении давления $\mathrm{O}_{2}$. Результаты спектроскопии комбинационного рассеяния света дополнительно подтвердили фазовые вариации оксидных наночастиц на основе меди. Рентгеновская фотоэлектронная спектроскопия подтвердила изменение энергии связи в степени окисления наночастиц. Оптическая ширина запрещенной зоны осажденного $\mathrm{Cu}_{2} \mathrm{O}$ составила $2.12 \mathrm{eV}$, а у $\mathrm{CuO}-1.79-1.82 \mathrm{eV}$.
\end{abstract}

Ключевые слова: вакуумная дуга, оксиды, наночастицы, плазмохимические реакции.

DOI: 10.21883/JTF.2021.12.51764.157-21

\section{Введение}

Использование наночастиц (НЧ) различных материалов и их химических соединений дает значительные преимущества благодаря их размерам и уникальным физико-химическим свойствам. Практически во всех случаях метод синтеза должен обеспечивать получение наночастиц с узким распределением по размерам, минимальный размер частиц, химическую чистоту и, следовательно, их специфические свойства [1-5].

$\mathrm{B}$ последние годы синтез и области применения $\mathrm{Cu}_{2} \mathrm{O}$ и $\mathrm{CuO}$ с контролируемыми размерами и морфологией продолжают интенсивно исследоваться [6]. $\mathrm{CuO}$ является более стабильным оксидом, чем $\mathrm{Cu}_{2} \mathrm{O}$, вследствие большей стабильности ионов $\mathrm{Cu}(\mathrm{II})$ в окружающей среде. Несмотря на это, как $\mathrm{CuO}$, так и $\mathrm{Cu}_{2} \mathrm{O}$ благодаря низкой ширине запрещенной зоны, высокому оптическому поглощению и каталитической активности, имеют области широкого практического применения, наиболее важными из которых являются фотоэлектрические системы [7], газовые сенсоры [8], различные гетерогенные катализаторы [9]. Кроме того, оксиды меди нетоксичны [10], обладают низкой стоимостью и возможностью большого разнообразия морфологических форм при синтезе [11]. Одним из наиболее эффективных способов получения нанодисперсных материалов остается газофазный синтез и, в частности, метод испарения-конденсации [12-14].

Целью настоящей работы является исследование процессов вакумно-дугового синтеза оксида меди при раз- личных значениях парциального давления кислорода, исследование влияния этого параметра на фазовый состав формирующихся наночастиц, а также характеризация синтезируемых продуктов спектроскопическими методами.

\section{1. Методика эксперимента}

Экспериментальная установка и зависимость свойств порошка от условий распыления подробно обсуждаются в [15-18]. Наночастицы оксида меди наносили на подложку из нержавеющей стали с помощью дугового распыления с использованием катода из меди М0. В качестве плазмообразующего газа использовался аргон, который подавался через испаритель и создавал в камере базовое давление $80 \mathrm{~Pa}$. В качестве реакционного газа использовался кислород. Синтез наночастиц исследовался при парциальном давлении кислорода 10 , 20, 30 и 40\%. Кислород подавался в реактор таким образом, чтобы образовать однородную оболочку вокруг плазменного факела. Наработка порошка происходила в течение $15 \mathrm{~min}$, и после прогрева камеры $(30 \mathrm{~min})$ осажденный в процессе синтеза порошок снимали с подложки пластиковым скребком.

Исследование фазового состава полученных образцов проводили методом рентгеновской порошковой дифракции на оборудовании Bruker D8 Advance в $\mathrm{CuK}_{\alpha}$ монохроматизированном излучении $(\lambda=0.15406 \mathrm{~nm})$. Образцы, помещаемые в кювету дифрактометра, представляли собой порошок, снятый скребком с подложки после 
напыления. Такой порошок имеет случайный характер ориентации отдельных наночастиц и их агломератов. Количественный структурно-фазовый анализ дифрактограмм проведен с помощью программы полнопрофильного анализа Powder Cell 2.4. Средние параметры кристаллической решетки определялись методом Шеррера по дифракционным пикам с использованием уравнения $d=K \lambda / \beta \cos \theta$. Для идентификации рентгенограмм использованы базы данных PDF-4+ от International Centre for Diffraction Data (ICDD).

Рамановские исследования проводились на спектрометре комбинационного рассеяния Bruker RFS 100/S. В качестве источника возбуждения использовался $\mathrm{Nd}$-YAG-лазер с $\lambda=532 \mathrm{~nm}$ при выходной мощности $8 \mathrm{~mW}$ в диапазоне $50-800 \mathrm{~cm}^{-1}$.

Исследования методом рентгеновской фотоэлектронной спектроскопии проводились на сверхвысоковакуумном фотоэлектронном спектрометре PHOIBOS 150MCD9, SPECS Gmbh при возбуждении излучением $\mathrm{AlK}_{\alpha}$ рентгеновской трубки. Для количественного анализа использовалось программное обеспечение Casa XPS.

Оптические измерения проводились на спектрофотометре Perkin Elmer Lambda 950 с получением спектров пропускания. Образцы для исследования были приготовлены совместным с бромидом калия и снятыми с подложки наночастицами (в соотношении $1: 100$ ) прессовании таблеток диаметром $13 \mathrm{~mm}$ и толщиной $0.55 \mathrm{~mm}$.

\section{2. Результаты и обсуждение}

На рис. 1 показаны рентгеновские дифрактограммы НЧ оксида меди при различных парциальных давлениях $\mathrm{O}_{2}$ от 10 до 40\%. Приведенные дифрактограммы демонстрируют образование трех различных фаз оксида меди при изменении парциального давления $\mathrm{O}_{2}$. При осаждении НЧ при парциальном давлении $10 \% \mathrm{O}_{2}$

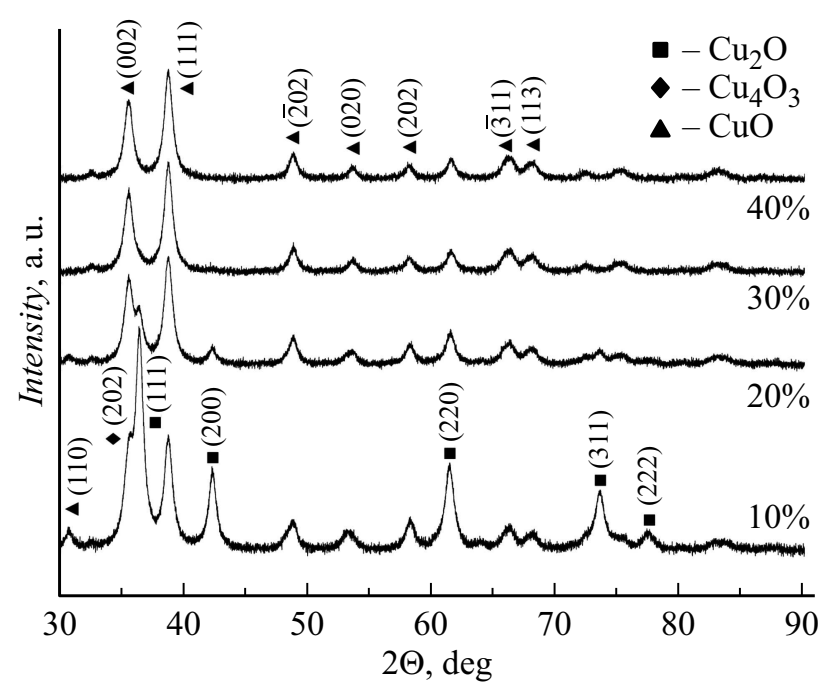

Рис. 1. Рентгеновские дифрактограммы НЧ оксида меди, осажденных при различных парциальных давлениях кислорода.

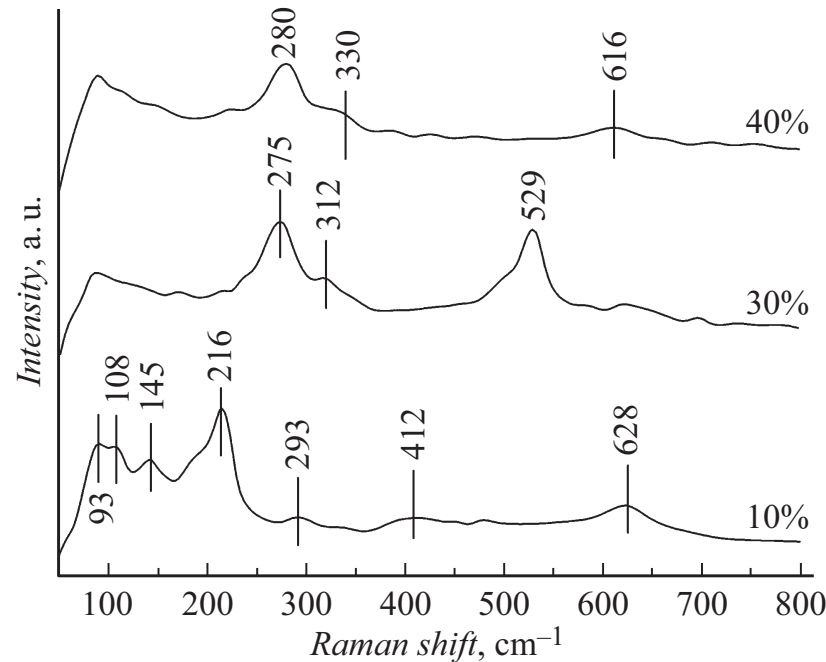

Рис. 2. Спектры комбинационного рассеяния НЧ оксида меди, осажденных при различных парциальных давлениях кислорода.

были получены три основных дифракционных пика при $36.5^{\circ}, 42.4^{\circ}$ и $61.4^{\circ}$, которым соответствуют кристаллические плоскости отражения (111), (200) и (220) для фазы $\mathrm{Cu}_{2} \mathrm{O}$ [PDF-4+ № 78-2076]. Дифракционные пики смешанных фаз $\mathrm{Cu}_{4} \mathrm{O}_{3}$ и $\mathrm{CuO}$ появляются при $35.7^{\circ}$ и $38.6^{\circ}$, что соответствует кристаллическим плоскостям (202) для фазы парамелаконита $\mathrm{Cu}_{4} \mathrm{O}_{3}$ [PDF-4+ № 04-007-2184] и (111) для фазы $\mathrm{CuO}$ соответственно. Когда давление $\mathrm{O}_{2}$ увеличивается до 20\%, соответствующие дифракционные пики $\mathrm{Cu}_{2} \mathrm{O}$ исчезают. Дальнейшее увеличение парциального давления $\mathrm{O}_{2}$ до 40\% приводит к образованию монофазных $\mathrm{HЧ} \mathrm{CuO}$, а наблюдаемые дифракционные пики при $35.6^{\circ}, 38.6^{\circ}$ и $48.8^{\circ}$ подтверждают ориентацию кристаллических плоскостей (002), (111) и (-202) для фазы CuO [PDF-4+ № 45-0937].

C использованием уравнения Дебая-Шеррера были рассчитаны области когерентного рассеяния (ОКР) наночастиц $\mathrm{Cu}_{2} \mathrm{O}$ и $\mathrm{CuO}$. Полученные значения ОКР, отождествляемые с размером кристаллитов, практически не изменялись с увеличением давления $\mathrm{O}_{2}$ и составляли $12 \mathrm{~nm}$. Процентное содержание кислорода не оказывало влияние на значения ОКР. Здесь определяющую роль играет величина общего давления, о чем более подробно можно ознакомиться в предшествующих работах [15,17-19]. Дополнительно, в этих работах приведено сопоставление результатов вычисленного из рентгенограмм среднего размера ОКР с результатами просвечивающей электронной микроскопии. Среди НЧ $\mathrm{CuO}$ лучшую кристалличность показывают осажденные при давлении $40 \% \mathrm{O}_{2}$.

Рамановская спектрометрия является дополнительным методом для определения фазовой структуры НЧ. Влияние парциальных давлений $\mathrm{O}_{2}$ на формирование структуры осажденных НЧ было дополнительно изучено с помощью анализа комбинационного рассеяния света (рис. 2). Наиболее доминирующий пик возникает при 
$216 \mathrm{~cm}^{-1}$ для НЧ, осажденных при давлении $10 \% \mathrm{O}_{2}$, что соответствует рамановской моде второго порядка $\left(2 \Gamma_{12}^{-}\right) \mathrm{Cu}_{2} \mathrm{O}$. Пик при $145 \mathrm{~cm}^{-1}$ можно отнести к комбинационному рассеянию света на фононах симметрии $\mathrm{F}_{1 u}$. Пик при $108 \mathrm{~cm}^{-1}$ отнесен к неактивному рамановскому режиму. Слабый пик при $412 \mathrm{~cm}^{-1}$ соответствует четырехфононной моде $\left(3 \Gamma_{12}-+\Gamma_{25}-\right)$. Кроме того, слабый пик, расположенный при $293 \mathrm{~cm}^{-1}$, связан с обертонной модой второго порядка симметрии $\mathrm{A}_{2 u}$. Умеренный пик на $628 \mathrm{~cm}^{-1}$ относится к активному инфракрасному режиму. Небольшой пик при $93 \mathrm{~cm}^{-1}$ был обнаружен для дефектов, резонансного возбуждения и нестехиометрии в НЧ $\mathrm{Cu}_{2} \mathrm{O}$. Эти наблюдаемые моды колебаний подтверждают наличие фазы $\mathrm{Cu}_{2} \mathrm{O}$ с кубической структурой в пространственной группе $\mathrm{O} h^{4}$ с двумя формульными единицами на элементарную ячейку. Рамановский спектр НЧ, осажденных при парциальном давлении $30 \% \mathrm{O}_{2}$, показывает характерные пики при 275,320 и $529 \mathrm{~cm}^{-1}$. Сильный пик при $275 \mathrm{~cm}^{-1}$ с пиком на плече при $320 \mathrm{~cm}^{-1}$ соответствует рамановской моде $\mathrm{A}_{g}$ и $\mathrm{B}_{g}^{1} \mathrm{CuO}$ соответственно. Другой пик наблюдается при $529 \mathrm{~m}^{-1}$, который приписывается рамановской моде $\mathrm{A}_{1 g}$ фазы парамелаконита $\mathrm{Cu}_{4} \mathrm{O}_{3}$. Следовательно, это подтверждает образование двухфазной системы $\mathrm{CuO}$ и $\mathrm{Cu}_{4} \mathrm{O}_{3}$. Это хорошо согласуется с результатами рентгеновской дифракции. НЧ, полученные при 40\% парциальном давлении $\mathrm{O}_{2}$, демонстрируют три пика при 280, 330 и $616 \mathrm{~cm}^{-1}$, что соответствует режиму комбинационного рассеяния $\mathrm{A}_{g}, \mathrm{~B}_{g}^{1}$ и $\mathrm{B}_{g}^{2} \mathrm{CuO}$ соответственно. По результатам $\mathrm{CuO}$ принадлежит к пространственной группе $\mathrm{C}_{2 h}^{6} \mathrm{c}$ моноклинной структурой из двух молекул на примитивную ячейку. Комбинация рентгеноструктурного анализа и рамановских исследований прямо устанавливает фазовый состав, существующий в осажденных НЧ оксида меди, как функцию парциального давления $\mathrm{O}_{2}$.

Синтез однофазных НЧ оксида меди является сложной задачей, так как изменение парциального давления имеет очень маленькое окно (около 10\%) для достижения определенной фазы. Это связано с тем, что при увеличении парциального давления $\mathrm{O}_{2}$ длина свободного пробега распыленных атомов меди уменьшается, что, в свою очередь, снижает скорость осаждения НЧ [20-23].

Метод рентгеновской фотоэлектронной спектроскопии (РФЭС) использовался для подтверждения химического состояния составляющих элементов в подготов-

Таблица 1. Относительная атомная концентрация меди, кислорода и углерода, вычисленная из обзорных спектров

\begin{tabular}{c|c|c|c}
\hline \multirow{2}{*}{$\begin{array}{c}\text { Парциальное } \\
\text { давление кислорода, \% }\end{array}$} & \multicolumn{3}{|c}{ Содержание элемента, at.\% } \\
\cline { 2 - 4 } & $\mathrm{Cu}$ & $\mathrm{O}$ & $\mathrm{C}$ \\
\hline 10 & 40.7 & 28.1 & 31.2 \\
20 & 38.2 & 25.1 & 36.7 \\
30 & 37.1 & 27.1 & 35.8 \\
40 & 35.1 & 34.0 & 30.9
\end{tabular}
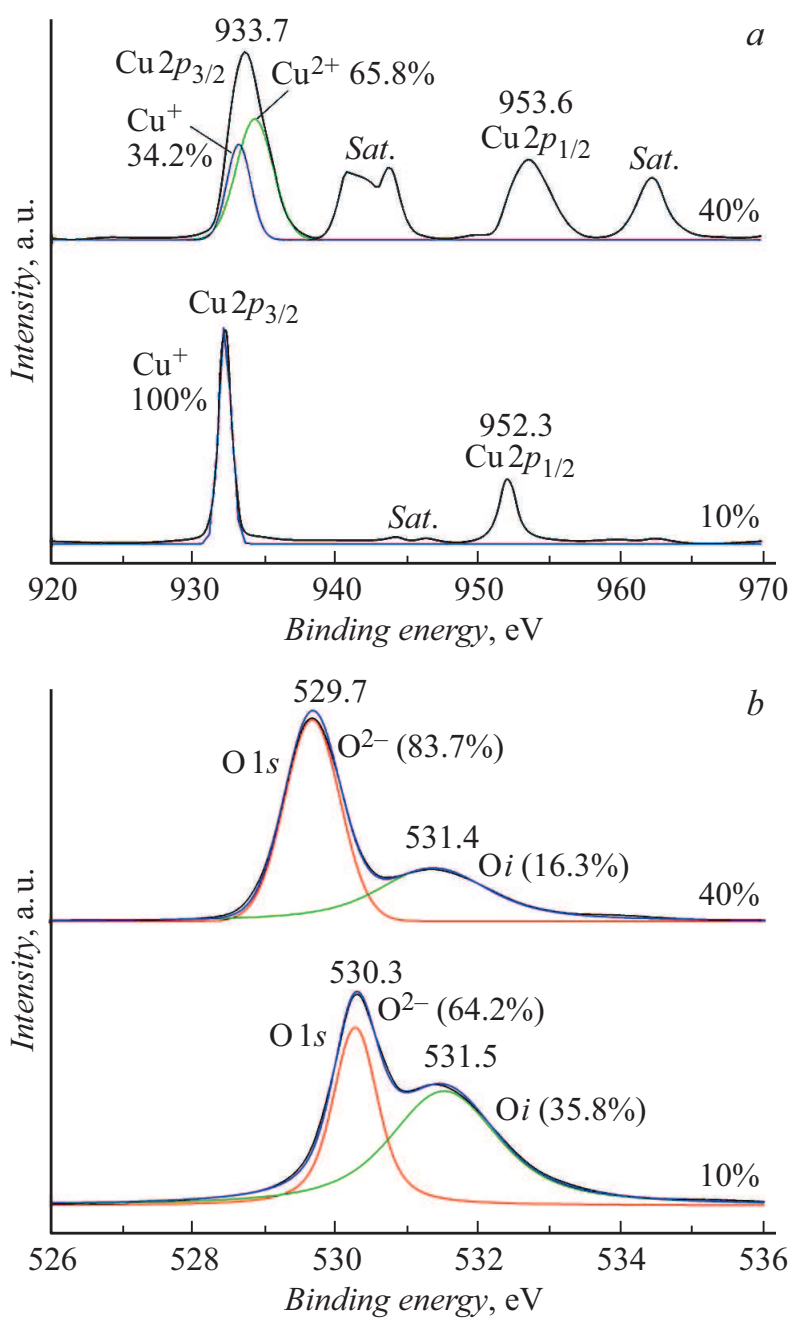

Рис. 3. Спектры РФЭС в узком сканировании $\mathrm{Cu} 2 p$ (a) и $\mathrm{O} 1 s(b)$ НЧ оксида меди, осажденных при различных парциальных давлениях кислорода.

ленных образцах. На поверхности НЧ обнаруживаются только три элемента, а именно $\mathrm{Cu}, \mathrm{O}$ и С. В табл. 1 представлены значения относительной атомной концентрации меди, кислорода и углерода, вычисленные из обзорных спектров образцов (в работе не приведены), синтезированных при различных значениях парциального давления кислорода. Углерод присутствует в положении пика $\mathrm{C} 1 s(284.8 \mathrm{eV})$ - неизбежно адсорбированный образцами из атмосферы, либо непосредственно в процессе получения из вакуумного масла.

Метод РФЭС позволяет работать только с поверхностным слоем, при котором большая часть сигнала $(95 \%)$ поступает с глубины менее $8 \mathrm{~nm}$ от поверхности. В этой связи для анализа фазового состава образцов недостаточно данных об атомных процентах, поскольку на результат влияет любая перегруппировка атомов, приводящая к образованию соединений на поверхности наночастиц, поэтому для установления фазового состава оксидных наночастиц были изучены спектры РФЭС с узким сканированием остовных уровней $\mathrm{Cu} 2 p$ и $\mathrm{O} 1 s$ (рис. 3). 
Таблица 2. Количественный анализ РФЭС спектров остовных уровней $\mathrm{Cu} 2 p_{3 / 2}$ и $\mathrm{O} 1 s$

\begin{tabular}{c|c|c|c|c}
\hline $\begin{array}{c}\text { Условия } \\
\text { получения }\end{array}$ & $\begin{array}{c}\text { Фотоэлектронная } \\
\text { линия }\end{array}$ & $\begin{array}{c}\text { Значение энергии } \\
\text { связи, } \mathrm{eV}\end{array}$ & $\begin{array}{c}\text { Процентное } \\
\text { содержание, } \%\end{array}$ & $\begin{array}{c}\text { Состояние } \\
\text { атома }\end{array}$ \\
\hline \multirow{2}{*}{$40 \% \mathrm{O}_{2}$} & $\begin{array}{c}\mathrm{Cu} 2 p_{3 / 2} \\
934.6\end{array}$ & 932.7 & 34.2 & $\mathrm{Cu}+$ \\
\cline { 2 - 5 } & О1s & 65.8 & $\mathrm{Cu}^{2+}$ & $\mathrm{O}_{2-}$ \\
\cline { 2 - 5 } & Плечевой пик & 530.3 & 16.3 & $\mathrm{O}^{2}$ \\
\cline { 2 - 5 } & Си2 $p_{3 / 2}$ & 531.5 & 100 & $\mathrm{Cu}^{+}$ \\
\cline { 2 - 5 } & О1s & 932.7 & 64.2 & $\mathrm{O}_{2-}$ \\
\cline { 2 - 5 } & Плечевой пик & 529.7 & 35.8 & $\mathrm{O}_{2}$
\end{tabular}

РФЭС спектры остовного уровня $\mathrm{Cu} 2 p$ показывают, что фотоэлектронные пики, относящиеся к $\mathrm{Cu} 2 p_{3 / 2}$ и $\mathrm{Cu} 2 p_{1 / 2}$, наблюдаются при 932.2 и $952.3 \mathrm{eV}$ соответственно для НЧ с преобладанием $\mathrm{Cu}_{2} \mathrm{O}$ фазы (полученных при $10 \% \mathrm{O}_{2}$ ). Аналогично, те же пики обнаруживаются при 933.7 и $953.6 \mathrm{eV}$ для НЧ фазы $\mathrm{CuO}$ (полученных при 40\% $\mathrm{O}_{2}$ ). Ионы $\mathrm{Cu}^{+}$в $\mathrm{HЧ} \mathrm{Cu}_{2} \mathrm{O}$ имеют высокий интенсивный пик в положении $2 p_{3 / 2}$ по сравнению с ионами $\mathrm{Cu}^{2+}$ в $\mathrm{HЧ} \mathrm{CuO}$. Помимо основных пиков энергии связи, также наблюдаются сателлитные пики. Это связано с разными типами частиц, связывающих $\mathrm{Cu}$ и О, или степенями окисления $\mathrm{Cu}^{+}$ и $\mathrm{Cu}^{2+}$. Для $\mathrm{HЧ} \mathrm{Cu}_{2} \mathrm{O}$ также наблюдаются некоторые небольшие слабые сателлитные пики на стороне с более высокой энергией связи в диапазоне 944-946 eV. Точно также НЧ $\mathrm{CuO}$ имеют сильные и широкие сателлитные пики, расположенные в диапазоне от 940 до $944 \mathrm{eV}$, что соответствует дублетным состояниям окисления $\mathrm{Cu}^{2+}$. Наряду с этим для фазы $\mathrm{CuO}$ также наблюдается одиночный сателлитный пик при $962.3 \mathrm{eV}$.

Было обнаружено, что пик $\mathrm{Cu} 2 p_{3 / 2}$ смещается в сторону более высоких значений энергии связи от 932.2 до $933.7 \mathrm{eV}$, когда парциальное давление $\mathrm{O}_{2}$ увеличивается с 10 до 40\%. Это указывает на изменение степени окисления $\mathrm{Cu} \mathrm{c} \mathrm{Cu}^{+}$на $\mathrm{Cu}^{2+}$. Изменения энергии связи подтверждаются пиками $\mathrm{Cu} 2 p_{3 / 2}$, наблюдаемыми как для $\mathrm{HЧ} \mathrm{Cu}_{2} \mathrm{O}$, так и для однофазных НЧ $\mathrm{CuO}$.

Из спектра O1s осажденных НЧ видно, что основной пик O1s обнаруживается при 530.3 и $529.7 \mathrm{eV}$ для НЧ оксида меди, синтезированных при 10 и 40\% соответственно. Кроме того, плечевые пики также наблюдаются при 531.5 и $531.4 \mathrm{eV}$. Было обнаружено, что пик O1s немного смещается в сторону более низкой энергии связи от 530.3 до $529.7 \mathrm{eV}$, когда парциальное давление $\mathrm{O}_{2}$ увеличивается с 10 до 40\%. Более низкие пики энергии связи могут быть отнесены к компонентам связывания $\mathrm{Cu}$ и $\mathrm{O}$ в оксидах меди, тогда как пики с более высокими плечами энергии связи обусловлены хемосорбированным кислородом $(\mathrm{O} i)$ на поверхности.
В табл. 2 представлены результаты количественного анализа РФЭС спектров остовных уровней $\mathrm{Cu} 2 p_{3 / 2}$ и $\mathrm{O} 1 s$. Из представленных данных отмечается присутствие атомов кислорода в состоянии $\mathrm{Cu}^{+}$в образцах, полученных при парциальном давлении $\mathrm{O}_{2} 40 \%$, по-видимому, свидетельствующее о присутствии фазы $\mathrm{Cu}_{2} \mathrm{O}$ в поверхностном слое наночастиц.

Полученные результаты РФЭС дополняют результаты рентгеновской дифракции, Рамана и энергодисперсионного анализа, обсужденные ранее, а также хорошо согласуются с данными, представленными в работах [24-27].

Спектры пропускания осажденных НЧ при различных парциальных давлениях $\mathrm{O}_{2}$ показаны на рис. 4 .

Обнаружено, что оптическое пропускание осаждаемых наночастиц зависит только от их фазового состава, определяемого значением парциального давления $\mathrm{O}_{2}$ при синтезе. Необходимо отметить, что при всех режимах средний диаметр НЧ поддерживается на уровне около $12 \mathrm{~nm}$. Коэффициент пропускания уменьшается с увеличением парциального давления $\mathrm{O}_{2}$. В частности, НЧ, осажденные при $10 \%$ парциального давления $\mathrm{O}_{2}$, имеют, из-за недостатка $\mathrm{O}_{2}$, высокий средний коэффициент пропускания - около $80 \%$ в ближней инфракрасной области. НЧ, осажденные при парциальном давлении $40 \% \mathrm{O}_{2}$, демонстрируют средний коэффициент пропускания - 60\%. Пропускание образцов с $\mathrm{Cu}_{2} \mathrm{O}$ резко снижается с длины волны ниже $600 \mathrm{~nm}$. Аналогично спектры пропускания $\mathrm{CuO}$ имеют край поглощения с критической длиной волны около $700 \mathrm{~nm}$. Все полученные НЧ обладают поглощающей способностью видимого света. Что касается небольших колебаний на спектре оксида меди, полученного при парциальном давлении кислорода $10 \%$, то, по-видимому, их можно объяснить разницей показателей преломления между оксидными наночастицами и подложкой [28].

Многочисленные исследования оксидов меди $\mathrm{Cu}_{2} \mathrm{O}$ (см., например, [29,30]) показали, что для них характерны прямые межзонные переходы. Что касается $\mathrm{CuO}$, то по результатам исследований оптического поглощения оксиды $\mathrm{Cu}(\mathrm{II})$ являются полупроводниками 

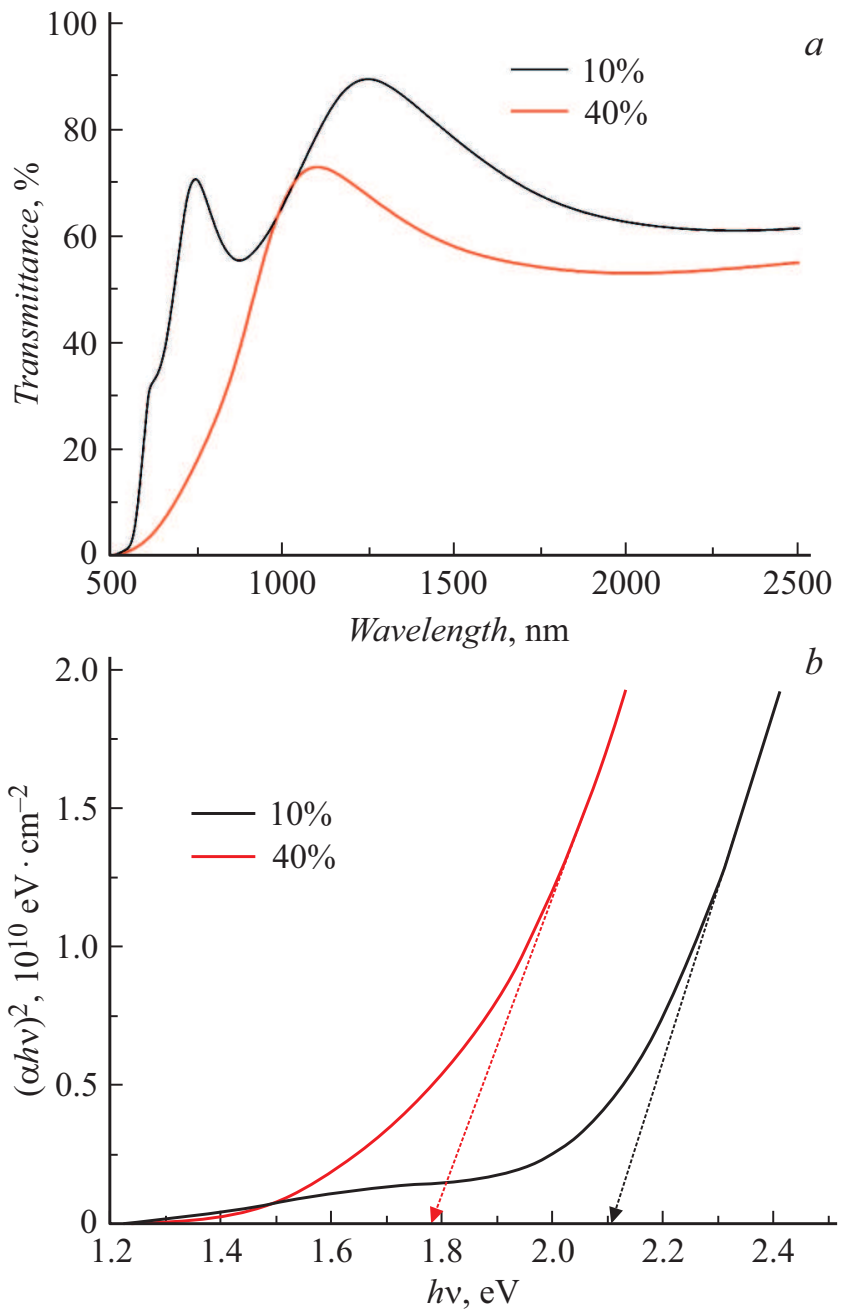

Рис. 4. Спектры пропускания $(a)$ и график Таука (b) НЧ оксида меди при различном парциальном давлении кислорода.

с энергетической щелью в диапазоне $\sim 1-2 \mathrm{eV}$ (см., например, [31]). Однако с теоретической точки зрения, расчет электронной структуры $\mathrm{CuO}$ является сложной задачей [32] и воспроизводимых результатов точных значений запрещенной зоны, а также характера зонного перехода, опубликовано не было. В работе [33] были построены диаграммы зонной структуры различных фаз оксида меди и получены расчетные значения ширины запрещенной зоны для непрямого перехода в $\mathrm{CuO}$. При этом авторы этой работы отдельно отмечают хорошее согласие с экспериментом для $\mathrm{Cu}_{2} \mathrm{O}$ и расхождения для $\mathrm{CuO}$.

Тем не менее в настоящей работе ширина запрещенной зоны обоих оксидов определяется моделью параболических зон Таука с использованием соотношения

$$
\alpha h v=A(h v-E g)^{n / 2},
$$

где $A-$ пропорциональная константа, $n-$ зависит от характера перехода ( $n=1$ для прямого разрешенного перехода), $h v$ - энергия падающего фотона, $\alpha-$ коэффициент поглощения, а $E_{g}$ - ширина оптической запрещенной зоны. Здесь коэффициент поглощения $\alpha$ напрямую связан с коэффициентом пропускания $(T)$ и диаметром $(d)$ НЧ. Коэффициент поглощения $\alpha$ можно оценить из следующего соотношения [34]:

$$
\alpha=\frac{1}{d} \ln \left[\frac{1}{T}\right],
$$

где $T-$ коэффициент пропускания, $d-$ средний диаметр НЧ.

На рис. $4, b$ показаны графики Таука (зависимости $(\alpha h v)^{2}$ от энергии фотонов $\left.h v\right)$ осажденных НЧ при различных парциальных давлениях $\mathrm{O}_{2}$.

Пересечение прямой с осью $h v$ в нуле определяет ширину запрещенной зоны $\left(E_{g}\right)$ для разрешенного оптического перехода. Образцы наночастиц, имеющие преобладающую фазу $\mathrm{Cu}_{2} \mathrm{O}$ (осажденные при $10 \%$ парциального давления $\mathrm{O}_{2}$ ), показывают значение ширины запрещенной зоны $2.12 \mathrm{eV}$. Ширина запрещенной зоны НЧ $\mathrm{CuO}$, осажденных при $40 \%$, составила $1.82 \mathrm{eV}$. Полученные значения хорошо согласуются с результатами, представленными в работах [35,36].

\section{Заключение}

Таким образом, в работе изучено влияние парциального давления кислорода в газовой смеси плазмохимического реактора на соотношение формирующихся кристаллических фаз наночастиц оксида меди. Комплекс рентгеновских и спектроскопических методов исследований подтвердил вариации фазового состава синтезируемых оксидных наночастиц в зависимости от парциального давления кислорода. С ростом концентрации $\mathrm{O}_{2}$ происходит трансформация структуры наночастиц с состава $\mathrm{Cu}_{2} \mathrm{O}$ и $\mathrm{Cu}_{3} \mathrm{O}_{4}$ до монофазы $\mathrm{CuO}$. Фотоэлектронные спектры демонстрируют, во первых, сильное загрязнение поверхности наночастиц адсорбированным углеродом, что может быть вызвано масляной системой вакуумирования технологической установки, а во вторых, присутствие частиц фазового состава $\mathrm{Cu}_{2} \mathrm{O}$ в поверхностном слое фазы $\mathrm{CuO}$, как следствие недостаточного насыщения кислородом образующихся в результате дугового испарения кластеров меди. Результаты определения ширины запрещенной зоны для разрешенного оптического перехода наночастиц $\mathrm{Cu}_{2} \mathrm{O}$ и $\mathrm{CuO}$, составившие $2.12 \mathrm{eV}$ и $1.82 \mathrm{eV}$ соответственно, хорошо согласуются с литературными данными. Однако определение характера зонного перехода и значения ширины запрещенной зоны для наночастиц $\mathrm{CuO}$ требуют дополнительных исследований, поскольку традиционные методы в рамках теории функционала плотности не могут описать это соединение, как полупроводник. Вместе с тем результаты таких исследований могли бы приблизить практическое использование оксидов меди в фотоэлектрических устройствах. 


\section{Финансирование работы}

Исследование выполнено за счет гранта Российского научного фонда (проект № 20-19-00021). Оптические исследования проведены в центре коллективного пользования Сибирского федерального университета при поддержке Государственного задания министерства науки и высшего образования Российской Федерации (FSRZ2020-0011).

\section{Конфликт интересов}

Авторы заявляют, что у них нет конфликта интересов.

\section{Список литературы}

[1] C.M. Niemeyer. Angew. Chem. Int. Ed., 40 (22), 4128 (2010). DOI: 10.1002/1521-3773(20011119)40:22

[2] W. Ma, L. Xu, A.F. de Moura, X. Wu, H. Kuang, C. Xu, N.A. Kotov. Chemical Rev., 117 (12), 8041 (2017). DOI: 10.1021 acs.chemrev.6b00755

[3] L. Mohammed, H.G. Gomaa, D. Ragab, J. Zhu. Particuology, 30, 1 (2017). DOI: 10.1016/j.partic.2016.06.001

[4] W. Xiang, Y. Liu, J. Yao, R. Sun. Physica E: Low-dimensional Syst., Nanostruct., 97, 363 (2018). DOI: 10.1016/j.physe.2017.12.016

[5] S.P. Jahromi, A. Pandikumar, B.T. Goh, Y.S. Lim, W.J. Basirun, H.N. Lim, N.M. Huang. RSC Adv., 5 (18), 14010 (2015). DOI: $10.1039 / C 4 R A 16776 G$

[6] P. Lignier, R. Bellabarba, R.P.R. Tooze. Chem. Soc. Rev., 41, 1708 (2012). DOI: $10.1039 / \mathrm{C} 1 \mathrm{CS} 15223 \mathrm{H}$

[7] Y. Abdu, A.O. Musa. J. Pure. Appl. Sci., 2, 8 (2009).

[8] K.J. Choi, H.W. Jang. Sensors (Basel, Switzerland, 2010), v. 10 , p. 4083 . DOI: $10.3390 / \mathrm{s} 100404083$

[9] M.B. Gawande, A. Goswami, F.-X. Felpin, T. Asefa, X. Huang, R. Silva, X. Zou, R. Zboril, R.S. Varma. Chem. Rev., 116, 3722 (2016). DOI: 10.1021/acs.chemrev.5b00482

[10] O. Bondarenko, K. Juganson, A. Ivask, K. Kasemets, M. Mortimer, A. Kahru. Archives of Toxicology, 87 (7), 1181 (2013). DOI: 10.1007/s00204-013-1079-4

[11] Q. Zhang, K. Zhang, D. Xu, G. Yang, H. Huang, F. Nie, C. Liu, S. Yang. Progress Mater. Sci., 60, 208 (2014). DOI: $10.1016 /$ j.pmatsci.2013.09.003

[12] F. Gao, X.J. Liu, J.S. Zhang, M.Z. Song, N. Li. J. Appl. Phys., 111, 084507 (2012). DOI: 10.1063/1.4704382

[13] Q. Yang, Z. GuO, X.H. Zhou, J.T. Zou, S.H. Liang. Mater. Lett., 153, 128 (2015). DOI: 10.1016/j.matlet.2015.04.045

[14] A.H. Jayatissa, K. Guo, A.C. Jayasuriya. Appl. Surf. Sci., 255, 9474 (2009). DOI: 10.1016/j.apsusc.2009.07.072

[15] И.В. Карпов, А.В. Ушаков, А.А. Лепешев, Л.Ю. Федоров. ЖТФ, 87 (1), 140 (2017). DOI: 10.21883/JTF.2021.12.51764.157-21 [I.V. Karpov, A.V. Ushakov, A.A. Lepeshev, L.Yu. Fedorov. Tech. Phys., 62 (1), 168 (2017). DOI: $10.1134 / \mathrm{S} 106378421701011 \mathrm{X}]$

[16] A.V. Ushakov, I.V. Karpov, A.A. Lepeshev. J. Superconductivity and Novel Magnetism, 30 (12), 3351 (2017). DOI: $10.1007 / \mathrm{s} 10948-017-4311-2$

[17] A.V. Ushakov, I.V. Karpov, A.A. Lepeshev, L.Yu. Fedorov. Int. J. Nanosci., 16 (4), 1750001 (2017). DOI: $10.1142 / \mathrm{S} 0219581 \mathrm{X} 17500016$
[18] I.V. Karpov, A.V. Ushakov, V.G. Demin, A.A. Shaihadinov, A.I. Demchenko, L.Yu. Fedorov, E.A. Goncharova, A.K. Abkaryan. J. Magnetism and Magnetic Materials, 490, 165492 (2019). DOI: 10.1016/j.jmmm.2019.165492

[19] A.V. Uschakov, I.V. Karpov, A.A. Lepeshev, M.I. Petrov. Vacuum, 133, 25 (2016). DOI: 10.1016/j.vacuum.2016.08.007

[20] X. Hu, F. Gao, Y. Xiang, H. Wu, X. Zheng, J. Jiang, J. Li, H. Yang, S. Liu. Mater. Lett., 176, 282 (2016). DOI: $10.1016 /$ j.matlet.2016.04.055

[21] S. Cui, E.C. Mattson, G. Lu, C. Hirschmugl, M. GajdardziskaJosifovska, J. Chen. J. Nanopart Res., 14, 744 (2012). DOI: 10.1007/s11051-012-0744-5

[22] S. Sério, M.E. Melo Jorge, M.J.P. Maneira, Y. Nunes. Mater. Chem. Phys., 126, 73 (2011). DOI: $10.1016 /$ j.matchemphys.2010.12.008

[23] E. Turgut, Ö. Coban, S. Sarıtas, S. Túzemen, M. Yıldırım, E. Gür. Appl. Surf. Sci., 435, 880 (2018). DOI: 10.1016/j.apsusc.2017.11.133

[24] Y. Alajlani, F. Placido, A. Barlow, H.O. Chu, S. Song, S.U. Rahman., R. De Bold, D. Gibson. Vacuum, 144, 217 (2017). DOI: 10.1016/j.vacuum.2017.08.005

[25] G. Murdoch, M. Greiner, M. Helander, Z. Wang, Z. Lu. Appl. Phys. Lett., 93 (8), 318 (2008). DOI: 10.1063/1.2966140

[26] T. Gaewdang, N. Wongcharoen. IOP Conf. Ser.: Mater. Sci. Eng., 211, 012025 (2017). DOI: $10.1088 / 1757-899 \mathrm{X} / 211 / 1 / 012025$

[27] A. Jilani, M.S. Abdel-Wahab, M.H.D. Othman, V. Sajith, A. Alsharie. Optik, 144, 207 (2017) DOI: 10.1016/j.ijleo.2017.06.075

[28] S. Cho. Met. Mater. Int., 19 (6) 1327 (2013). DOI: $10.1007 / \mathrm{s} 12540-013-6030-y$

[29] Д.А. Кудряшов, А.С. Гудовских, А.В. Бабичев, А.В. Филимонов, А.М. Можаров, В.Ф. Агекян, Е.В. Борисов, А.Ю. Серов, Н.Г. Философов. ФТП, 51 (1), 111 (2017). DOI: 10.21883/JTF.2021.12.51764.157-21 [D.A. Kudryashov, A.S. Gudovskikh, A.V. Babichev, A.V. Filimonov, A.M. Mozharov, V.F. Agekyan, E.V. Borisov, A.Yu. Serov, N.G. Filosofov. Semiconductors, 51 (1), 110 (2017). DOI: $10.1134 / \mathrm{S} 1063782617010110]$

[30] А.Б. Гордиенко, Ю.Н. Журавлев, Д.Г. Федоров. ФТТ, 49 (2), 216 (2007). [A.B. Gordienko1, Yu.N. Zhuravlev, D.G. Fedorov. Phys. Solid State, 49 (2), 223 (2007). DOI: $10.1134 / \mathrm{S} 1063783407020072]$

[31] D. Chauhan, V.R. Satsangi, S. Dass, R. Shrivastav. Bull. Mater. Sci., 29 (7), 709 (2007).

[32] B.K. Meyer, A. Polity, D. Reppin, M. Becker, P. Hering, P.J. Klar, Th. Sander, C. Reindl, J. Benz, M. Eickhoff, C. Heiliger, M. Heinemann, J. Bläsing, A. Krost, S. Shokovets, C. Müller, C. Ronning. Phys. Stat. Sol. B, 249 (8), 1487 (2012). DOI: 10.1002/pssb.201248128

[33] M. Heinemann, B. Eifert, C. Heiliger. Phys. Rev. B, 87, 115111 (2013). DOI: 10.1103/PhysRevB.87.115111

[34] M.T.S. Nair, L. Guerrero, O.L. Arenas, P.K. Nair. Appl. Surf. Sci., 150 (1-4), 143 (1999). DOI: 10.1016/S0169-4332(99)00239-1

[35] S.C. Ray. Solar Energy Materials and Solar Cells, 68 (3-4), 307 (2001). DOI: 10.1016/S0927-0248(00)00364-0

[36] A.Y. Oral, E. Menşur, M.H. Aslan, E. Başaran. Mater. Chem. Phys., 83 (1), 140 (2004). DOI: $10.1016 /$ j.matchemphys.2003.09.015 